Research Article

\title{
Higher Education, Technological Innovation, and Regional Sustainable Development: Insights from a VAR Model
}

\author{
Huajun $\mathrm{Li}^{1}$ and Si Liu $\mathbb{D}^{2}$ \\ ${ }^{1}$ School of Economics \& Management, Zhaoqing University, Zhaoqing 510006, China \\ ${ }^{2}$ Institute of Higher Education, Guangdong University of Technology, Guangzhou 510006, China \\ Correspondence should be addressed to Si Liu; sliu@gdut.edu.cn
}

Received 24 May 2021; Revised 22 June 2021; Accepted 24 August 2021; Published 20 September 2021

Academic Editor: Daqing Gong

Copyright (C) 2021 Huajun Li and Si Liu. This is an open access article distributed under the Creative Commons Attribution License, which permits unrestricted use, distribution, and reproduction in any medium, provided the original work is properly cited.

\begin{abstract}
Sustainable development has increasingly become a primary concern of governments in the stage of high-quality economic development. Taking as an example Guangdong Province, China, where development and polarization coexist, this study uses a Vector Autoregressive(VAR) model to examine the relationship between higher education, technological innovation, and economic growth, and then uses the Coupling Coordination (CC) model to evaluate the developing coordination of subsystems where the above three elements are located; furthermore, it summarizes the mechanisms and corresponding paths of higher education on the quantity and quality of economic growth and illustrates the interactive relationships, the dynamic mechanisms, and the influencing factors. The results show that there is a dynamic interaction mechanism between higher education, technological innovation, and regional economy. The effect of this mechanism is enhanced in developed areas and with an obvious circle cumulative effect, while partly inhibited in undeveloped areas and with less or no circle cumulative effect. Therefore, on the path towards high-quality development, endogenous development models should be formulated and strengthened by developing higher education and constructing an innovation system, especially in the undeveloped areas. Higher education should be more in the regional development framework and targeted at the interaction and synergy in the regional socioeconomic system.
\end{abstract}

\section{Introduction}

Looking at the research regarding the determinants of economic growth and practices of different countries, a basic conclusion can be made that human capital and technological progress are crucial to regional socio-economic development. In discussing how human capital and technological progress influence regional development, scholars have emphasized the importance of higher education. From the perspective of human capital theory, education and "Learning by Doing" are important formation mechanisms; in particular, higher education is an enhancement mechanism to improve the quality and structure of human capital [1-3]. From the perspective of innovation theory, Higher Education Institutions (HEIs) are embedded in regional innovation systems through scientific research and social services and make important contributions to regional economic development by promoting knowledge diffusion and technological transfers [4-6]. However, among the research regarding the specific mechanism of the interaction between higher education, technological innovation, and economic growth, different conclusions have been reached due to differences between countries, economic systems, and regional development. At the same time, with the background of sustainable development, more and more attention needs to be paid to regional coordinated and balanced development. While a moderate regional economic gap is conducive to promoting social and economic development, if the gap is too large, it will cause serious economic and social problems [7]. As the polarization phenomenon has a direct impact on the quality and fairness of social welfare, it indirectly affects the population quality.

Under the present economic situation, considering economic development from an overall perspective and with 
long-term interests in mind, as well as improving the quality of economic growth, have become major practical problems that are currently being explored by many countries and regions, and are also major research topics in various academic fields. Therefore, this paper chooses a local region (Guangdong Province) with typical polarized and unbalanced development in a developing country (China) as a case study.

China's social and economic development has made great achievements in the past four decades since the reforms and opening up. The country has maintained a relatively rapid growth rate after its financial crisis and has become the world's second largest economy as an economic aggregate. However, according to the data released by the International Monetary Fund, China's GDP per capita ranks 67th of 192 countries and regions and was lower than the global level in 2018 (the global level of GDP per capita was $\$ 11,305$; China's was \$9608). Therefore, as China's economic development enters a new stage, improving the quality and increasing the efficiency have become important practical and theoretical issues.

Since the reform and opening up in China, Guangdong Province has developed rapidly and was the first region to do so in the country in terms of GDP. It has remained the leading province for more than forty years. These achievements are attributable to a policy bonus from the reform and opening up, to the aggregation effect of talent and capital, and to the favorable environment of trade and business [7]. Meanwhile, these achievements have also shown the regional development model to be characterized by factor-driven, investment-driven, and disequilibrium factors. However, this development model has also raised dilemmas and challenges for regional sustainable development [8]. Therefore, in the era of a global focus on the quality and sustainability of economic development, it is of great significance to explore and analyze the formation mechanisms and countermeasures with respect to the abovementioned dilemmas and challenges for developing countries and regions.

The main contributions of this study are as follows: (1) Testing the relationships between higher education, technological innovation, and economic growth under the framework of regional sustainable development will be conducive to understanding and identifying the interaction mechanism and long-term effects of higher education on regional socio-economic development and innovation ecosystems; (2) using cross-validation, by combining empirical studies and practical performance analysis, this paper illustrates the disadvantages of path dependence in an unbalanced development model, which have long been obstacles to sustainable and high-quality development and have inhibited the significant function of higher education as a source of regional endogenous development drive in lessdeveloped areas; and (3) presenting detailed issues that should be fully addressed in policy design and implication from the perspectives of regional endogenous development drive, regional innovation ecosystems, and regional sustainable development, which are of great significance to developing countries and regions.

\section{Literature Review}

Understanding the factors that determine the economic growth of a country has always been a topic of great concern in the field of economics. Solow (1956) studied the reasons for economic growth in the United States during the period from 1909 to 1949 , and found that the greatest contribution to economic growth during this period was the joint contribution of knowledge, technology, and other factors [8]. His research prompted scholars to start paying attention to the impact of factors such as education, knowledge, and technology on economic growth [8]. Schultz, Becker, and Lucas studied the relationship between education and economic development from the perspective of human capital and emphasized that education and "Learn by Doing" were important mechanisms for human capital formation [1-3]. Technological progress, which was an exogenous variable in Solow's research, could not explain the phenomenon of regional economic growth differences; later, scholars took technological progress as an endogenous variable to form a new growth theory. Romer pointed out that technological progress is the result of capital and human capital, which can be invested in research and development, and he further found that knowledge accumulation was the key to long-term economic growth among the endogenous factors such as capital, labor, human capital, and technological level $[9,10]$. From the perspective of new growth theory, knowledge has become a decisive endogenous variable of regional economic growth, and the accumulation of knowledge depends on the investment of economic parties in research, development, education, and training.

Colleges and universities have innovative functions in the form of talent training, scientific research, social services, and cultural inheritance, and their importance is self-evident in the process of economic and social development. In the field of innovation, whether one considers national innovation system theory, regional innovation system theory, or triple helix theory, all have revealed the important role of universities in technological innovation and economic growth $[4-6,11,12]$. In the research mentioned above, the conclusions of the relevant scholars also indicated that higher education has an important impact on regional economic development. With the background of a developing knowledge economy and the promotion of universities' sci-tech parks in developed countries, the cooperation and interaction between universities and regional innovation and industrial development have been deepened $[13,14]$. Therefore, higher education is not only an important driving force of local social innovation but also an important channel of global innovation cooperation and more deeply integrated and embedded into the regional innovation ecosystem [15-17].

HEIs' promotion of regional economic development through human capital creation, research and development, knowledge sharing, technology transfer, and innovation environment creation has become the consensus of most existing studies [18]. Regional economic development is conducive to promoting the development of higher education by increasing the input in higher education and 
deepening cooperation among industries, universities, and research institutions, which has also been verified in many research projects [19].

However, must there be a two-way positive interaction between higher education and regional economic growth? This is not the case for the following reasons: firstly, due to the differences in economies and the degree of economic development, in reality, there is only a one-way causal relationship from higher education to economic growth or from economic growth to higher education [19]. Secondly, education investment as a human capital formation and accumulation path is constrained by conditions such as household income levels and credit support. As a result, the availability of endogenous human capital has become an important factor in social inequality and intergenerational transmission, which has further impacts on the development of higher education [20,21]. Thirdly, under the long-term unbalanced development model, the siphoning effect in a growth pole is being continuously strengthened when the diffusion effect and spillover effect are not being fully exerted, which results in a widening of the gap in regional economic development. Therefore, the above phenomenon has led HEIs in developed regions to obtain more resources and develop better than those in undeveloped regions [22]. Fourthly, higher education policies and differences in the resource allocation model and standard may indirectly lead to the "Matthew effect" presented as "the strong get stronger and the weak get weaker" both in higher education itself and income distribution [22-25]. Fifthly, further from the perspective of the impact of human capital structure on the industrial economy, the role of higher education is more complex. For example, higher education is an important mechanism to optimize the structure of human capital, and the optimization of the human capital structure is of great significance to rationalize and upgrade the industrial structure $[10,26,27]$. In addition, in the process of empirical research, differences in theoretical models, research variables, and methods can also lead to different results [28].

In summary, the relationship of higher education, technological innovation, and economic growth is dynamic and relatively complex. The economic differences and development models, human capital structure, regional innovation architecture, regional policies differences, and so on influence the interaction mechanism and effectiveness of higher education, technological innovation, and economic growth. In view of this, we explore the above relationship and dynamic mechanisms in the context of regional sustainable development and higher-quality economic development. As the research case of this article, Guangdong Province, as a local region of China, has the typical characteristics of fastest economic growing, largest economic aggregate, and the most uneven development in the country. Therefore, the following core research issues are structured as follows: the third part explores the relationship and dynamic mechanism of higher education, technological innovation, and economic growth by a focus on the quantity of economic growth; the fourth part further explores the above relationship and dynamic mechanism from the perspective of system and by a focus on the quality of economic development; the fifth part further discusses the influencing mechanism and path of the interaction relationships among the subsystems mentioned above by focus on the regional sustainable development and high-quality economic development.

\section{Relationship of Higher Education, Technological Innovation, and Economic Growth}

3.1. Methodology, Variables, and Data. From the literature review, we can see that there are dynamic relationships between higher education, technological innovation, and regional economic growth. Therefore, this part introduces the Vector Autoregressive (VAR) analysis method that considers every endogenous variable in the system as a function of the hysteresis value of all endogenous variables in the system in order to verify the above relationships $[28,29]$. The basic mathematical expressions for the $\operatorname{VAR}(p)$ model are as follows:

$$
y_{t}=\varphi_{1} y_{t-1}+\ldots+\varphi_{p} y_{t-p}+\eta x_{t}+\varepsilon_{t}, \quad t=1,2, \ldots, T,
$$

where $y_{t}$ is the column vector of the $\mathrm{k}$-dimensional endogenous variable, $x_{t}$ is the column vector of the d-dimensional exogenous variable, $p$ is the lag intervals for the endogenous, $t$ is the number of samples, $k \times k$ dimension matrix $\varphi_{1}, \ldots, \varphi_{p}$ and $k \times d$ dimension matrix $\eta$ are the coefficient matrix to be estimated, and $\varepsilon_{t}$ is the $K$-dimensional perturbed column vector [30].

Drawing on the ideas of relevant scholars, the scale of higher education (average number of students learning in ordinary colleges and universities), the number of patent applications granted, and the total GDP was selected as the indicators of higher education, technological innovation, and economic growth [31, 32]. In this paper, the VAR model is implemented with the operation of Eviews 9.0 software. Indicator data from 1998 to 2018 are selected as the sample for this study, taken from the corresponding year of the "China Statistical Yearbook" and "Guangdong Statistical Yearbook." The actual data of each index are taken as the Natural Logarithm and are represented as empirical analysis data. So, LNSCA, LNPT, and LNGDP represent the Natural Logarithm of raw data of the scale of higher education, the number of patent applications granted, and the total GDP, respectively.

3.2. Variable Unit Root Test. In this paper, the Augment Dickey-Fuller (ADF) method is used for the common unit root test. The results are shown in Table 1 . The $p$ values in the second-order difference sequence of LNGDP, LNPT, and LNSCA are all less than 1\%, which indicates that they belong to the second-order stationary series within the $99 \%$ confidence interval and can all be used to formulate the VAR model. 
TABle 1: Augment Dickey-Fuller (ADF) variable unit root test results.

\begin{tabular}{|c|c|c|c|}
\hline Variable & ADF test value ( $t$-statistic) & Probability & Test result (significant at $1 \%$ ) \\
\hline LNGDP & 1.663761 & 0.9717 & Unstable \\
\hline$\triangle \mathrm{LNGDP}$ & -0.655058 & 0.4200 & Unstable \\
\hline$\triangle^{2}$ LNGDP & -5.435805 & 0.0000 & Stable \\
\hline LNPT & -1.998460 & 0.2850 & Unstable \\
\hline$\triangle \mathrm{LNPT}$ & -3.967490 & 0.0075 & Stable \\
\hline$\triangle^{2} \mathrm{LNPT}$ & -5.321331 & 0.0006 & Stable \\
\hline LNSCA & -3.218777 & 0.0338 & Unstable \\
\hline$\triangle \mathrm{LNSCA}$ & -1.939330 & 0.3087 & Unstable \\
\hline$\triangle^{2} \mathrm{LNSCA}$ & -5.226506 & 0.0007 & Stable \\
\hline
\end{tabular}

$\Delta$ and $\triangle^{2}$, respectively, represent a first-order or second-order difference calculation for a variable.

3.3. Estimation of VAR Model. According to VAR methodology, the optimal lag order must be determined before the VAR model estimation. In this study, the optimal lag order of the lag is determined as 1 by AIC and SC (Table 2).
With the results of parameters estimated by the Eviews9.0 software (Table 3), the VAR (1) model is formulated as follows:

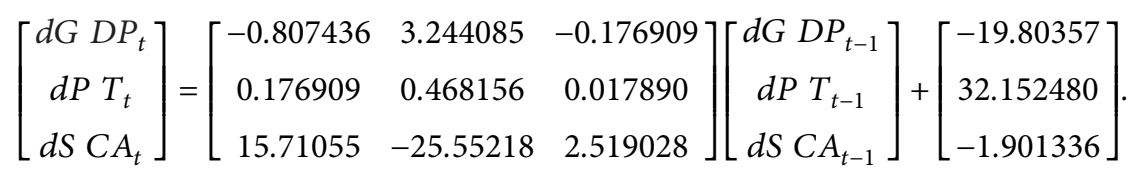

The close $R^{2}$ is to 1 , the better the equations in the model fit. As shown in Table 3, the estimated results indicate that the VAR (1) model established in this study has statistical significance. The results of the stationary test of the VAR (1) model show that all the characteristic roots of the model are in the unit circle (Figure 1), so the model of VAR (1) is a stationary one. The dynamical system based on the VAR model does not strictly distinguish between dependent variables and independent variables, so the significance of the unilateral process is not the focus of this study. Therefore, we can further analyze the relationship between the variables based on the model of VAR (1) and from the perspectives of Granger causality, impulse response, and variance decomposition.

Trace test and Max-eigenvalue test indicate 2 cointegrating eqn (s) at the 0.05 level (Tables 4 and 5).

After examination, the residual is stable. The result of the residual ADF test is shown in Table 6.

3.4. Granger Causality Test. The Granger causality test is a statistical explanation of the relationship between variables and is essentially a test of whether a variable's lag can be introduced into other variable equations [29]. Therefore, this study carries out the Granger causality test to distinguish between endogenous variables and exogenous variables (Table 7). The Granger causality test results of the VAR model show that LNSCA, LNPT, and LNGDP are Granger causes for each other. Therefore, this result supports the theoretical analysis in the literature review: HEIs provide talent and knowledge for technological innovation and economic growth through human capital accumulation and scientific research. In turn, technological innovation and economic development have also promoted the development of higher education through the demand for talent, the need for innovation cooperation, and the improvement of the economic environment.

3.5. Impulse Response Function and Variance Decomposition. A Granger causality test confirms that there exist important transmission mechanisms between higher education, technological innovation, and economic growth, but it does not provide clear information about the dynamic characteristics of this role. Therefore, based on the establishment of the VAR model, this study uses the impulse response function (IRF) and variance decomposition for further analysis. The impulse response function is used to describe the response of a system to an endogenous variable shock or innovation; the variance decomposition is used to decompose the response into the contribution of each variable shock in the system.

As seen from the impulse map (Figure 2), LNSCAL and LNPT have more obvious mediums and long-term effects on LNGDP, as well as LNSCAL on LNPT. In contrast to Figures 2(a) and 2(b), both higher education and technological innovation play important roles in economic growth. First, the effect of a positive impulse reaction is obvious and gradually decreases, then it turns negative, and finally, it converges to the trend of zero. At the same time, the effect of technological innovation on economic growth is greater than that of higher education. This result also indirectly verifies that the formation and accumulation mechanism of human capital has "doing secondary school" in addition to education. Comparing Figures 2(c) and 2(d), the response of LNPT to LNSCA is more obvious than to LNGDP, which indicates the impact of higher education on scientific and 
TABLE 2: Lag order for the Vector autoregression (VAR) model.

\begin{tabular}{lcccccc}
\hline Lag & Log L & LR & FPE & AIC & SC & HQ \\
\hline 0 & 91.81954 & NA & $1.75 \mathrm{e}-08$ & -9.349425 & -9.200303 & -9.324188 \\
1 & 207.8536 & $183.2118^{*}$ & $2.28 \mathrm{e}-13^{*}$ & $-20.61617^{*}$ & $-20.01969^{*}$ & $-20.51522^{*}$ \\
2 & 212.1617 & 5.441807 & $4.08 \mathrm{e}-13$ & -20.12229 & -19.07844 & -19.94563 \\
\hline
\end{tabular}

${ }^{*}$ indicates lag order selected by the criterion.

TABLE 3: VAR (1) model estimation results.

\begin{tabular}{|c|c|c|c|}
\hline Variable & LNGDP & LNPT & LNSCA \\
\hline $\operatorname{LNGDP}(-1)$ & $\begin{array}{c}-0.807436 \\
(0.38591) \\
{[-2.09226]}\end{array}$ & $\begin{array}{l}3.244085 \\
(1.44167) \\
{[2.25023]}\end{array}$ & $\begin{array}{c}-0.176909 \\
(0.03714) \\
{[-4.76358]}\end{array}$ \\
\hline LNPT(-1) & $\begin{array}{l}0.176703 \\
(0.05951) \\
{[2.96931]} \\
\end{array}$ & $\begin{array}{l}0.468156 \\
(0.22231) \\
{[2.10585]}\end{array}$ & $\begin{array}{l}0.017890 \\
(0.00573) \\
{[3.12394]} \\
\end{array}$ \\
\hline LNSCA $(-1)$ & $\begin{array}{l}15.71055 \\
(3.33397) \\
{[4.71226]}\end{array}$ & $\begin{array}{c}-25.55218 \\
(12.4548) \\
{[-2.05160]} \\
\end{array}$ & $\begin{array}{l}2.519028 \\
(0.32084) \\
{[7.85139]} \\
\end{array}$ \\
\hline $\mathrm{C}$ & $\begin{array}{c}-19.80357 \\
(4.27834) \\
{[-4.62880]}\end{array}$ & $\begin{array}{l}32.15248 \\
(15.9827) \\
{[2.01171]} \\
\end{array}$ & $\begin{array}{c}-1.901336 \\
(0.41172) \\
{[-4.61805]} \\
\end{array}$ \\
\hline $\mathrm{R}^{2}$ & 0.999133 & 0.994042 & 0.999149 \\
\hline
\end{tabular}

The significance level is 5\%; the values in brackets "()" are "Std. Error," and the values in square brackets "[ ]" are "t-Statistic."

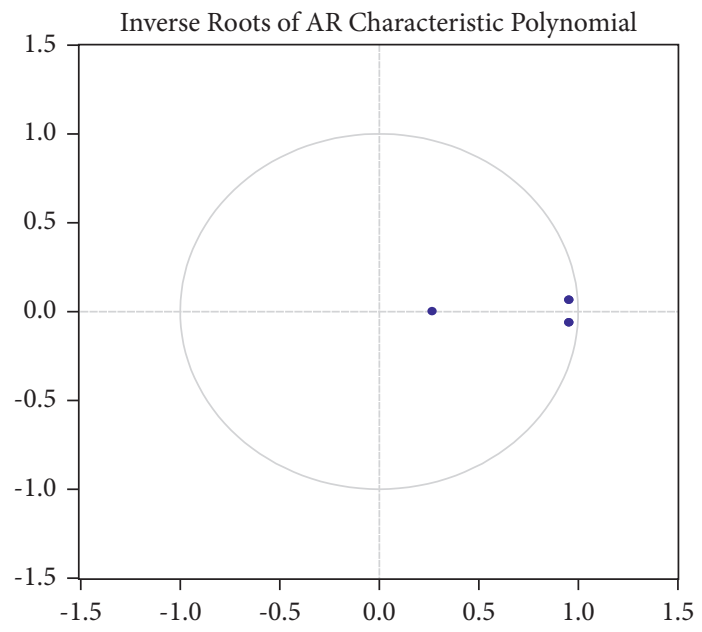

FIgURE 1: VAR (1) model stability test.

technological innovation is more obvious than that of economic growth. This result directly verifies that HEIs have directly and effectively promoted technological innovation through personnel training, scientific research, and participation in industry-university-research cooperation. Figure 2(d) reflects a short-term positive impulse reacting effect and a long-term negative impulse reacting effect on LNPT with respect to the influence of LNGDP; these results show that there is inconsistency between the two major systems of technological innovation and the social economy, and the improvement of the economic environment does not necessarily lead to an improvement of the innovation environment. Therefore, the planning of regional economic development strategy needs to pay attention to the construction of a regional innovation system and the optimization of an innovation ecological environment.

As seen from the results of the variance decomposition (Table 8), there is an evident inertia reaction to LNGDP that is caused by its own innovation or the innovations from LNPT and LNSCA. From the structural change of the variance decomposition, according to the period, the LNGDP's own inertial response rapidly weakens, and the contribution of LNPT rapidly increases while LNSCA slowly increases. Finally, the effect of innovation on LNGDP's own inertial response is kept at $31.86 \%$ or above, while the LNPT is kept at $56.49 \%$ and LNSCA is kept at $11.65 \%$. These results 
TABLE 4: Unrestricted cointegration rank test (trace).

\begin{tabular}{|c|c|c|c|c|}
\hline Hypothesized No. of CE (s) & Eigenvalue & Trace statistic & 0.05 critical value & Prob.** \\
\hline None* & 0.969315 & 99.3259 & 29.79707 & 0 \\
\hline At most $1^{*}$ & 0.901818 & 40.09829 & 15.49471 & 0 \\
\hline At most 2 & 0.037081 & 0.642356 & 3.841466 & 0.4229 \\
\hline
\end{tabular}

Trace test indicates 2 cointegrating eqn (s) at the 0.05 level ${ }^{*}$ denotes rejection of the hypothesis at the 0.05 level, ${ }^{* *}$ MacKinnon-Haug-Michelis (1999) $p$ values.

TABLE 5: Unrestricted cointegration rank test (maximum eigenvalue).

\begin{tabular}{lccc}
\hline Hypothesized No.of CE(s) & Eigenvalue & Trace statistic & 0.05 critical value \\
\hline None $^{*}$ & 0.969315 & 59.22761 & 21.13162 \\
At most $1^{*}$ & 0.901818 & 39.45593 & 14.2646 \\
At most 2 & 0.037081 & 0.642356 & 3.841466 \\
\hline
\end{tabular}

Max-eigenvalue test indicates 2 cointegrating eqn (s) at the 0.05 level. ${ }^{*}$ denotes rejection of the hypothesis at the 0.05 level. ${ }^{* *}$ denotes MacKinnon-HaugMichelis(1999) $p$ values.

TABLE 6: Result of residual ADF test.

\begin{tabular}{lcc}
\hline $\begin{array}{l}\text { Null Hypothesis: RESID02 has a unit root } \\
\text { Exogenous: None }\end{array}$ & \\
Lag Length: 0(Automatic-based on SIC, maxlag = 4) & $t$-Statistic & Prob.* $^{*}$ \\
& & -3.371986 \\
Augmented dickey-fuller test statistic & $1 \%$ level & -2.685718 \\
& $5 \%$ level & -1.959071 \\
Test critical values: & $10 \%$ level & -1.607456 \\
\end{tabular}

* denotes MacKinnon(1996) one-sided $p$ values.

show that technological innovation has a direct and strong influence on economic growth, while higher education has an indirect and long-term influence. This conclusion has an important implication for the current construction of the innovation ecosystem-that is, it should be combined and coordinated with relevant innovation elements from a short and long-term perspective.

\section{The Coordination of Higher Education, Technological Innovation, and the Industrial Economy in the Regional Socioeconomic System}

4.1. Coupling Coordination Model. In the last chapter, we studied the relationship between higher education, technological innovation, and economic growth with three single indicators. However, the abovementioned relationships are in fact, more complex, depending on the innovation ecosystem operation process or the regional sustainable development process. From the perspective of system theory, higher education, technological innovation, and the industrial economy are regarded as relatively independent subsystems in the larger system of the social economy [33]. Therefore, this chapter will further evaluate and validate the coordination of the subsystems mentioned above by using the coupling coordination degree model and combining more elements [34-36] and then further explore the relationship between higher education, technological innovation, and economic growth from the perspectives of regional sustainable development and high-quality economic development.

$$
C=\left[\frac{U_{1} \times U_{2} \times U_{3}}{\left(U_{1}+U_{2}+U_{3} / 3\right)}\right]^{(1 / 3)} .
$$

In the above formula, $\mathrm{C}$ represents the integrated socialeconomic systems' coupling, and $U_{i}(i=1,2,3)$ represents the comprehensive development level index of each subsystem. On this basis, the subsystem's contribution to the integrated system can be determined by the following linear weighting method formula:

$$
U_{i}=\sum_{j=1}^{n} w_{i j} u_{i j}, \text { where } \sum_{j=1}^{n} w_{i j}=1 .
$$

Coupling is denoted by $C \in[0,1]$. When $C=1$, the coupling degree of the system is maximized, indicating that benign resonance coupling is achieved in the subsystems. When $C=0$, the coupling degree of the system is minimal, indicating that the subsystems are in an independent state. Based on previous studies, the coupling degree is divided into five levels: low coupling $(0 \leq C<0.2)$; relatively low coupling $(0.2 \leq C<0.4)$; moderate coupling $(0.4 \leq C<0.6)$; relatively moderate coupling $(0.6 \leq C<0.8)$; highly coupled $(0.8 \leq C<1)$ [35].

In view of the different indicator standards contained in each subsystem and the interaction effect among the 
TABLE 7: Granger causality test results.

\begin{tabular}{|c|c|c|c|c|c|}
\hline Equation & Primary hypothesis & Chi-sq & df & Prob. & Testing results \\
\hline \multirow{3}{*}{ LNGDP } & LNPT cannot granger cause LNGDP & 0.00300 & 1 & 0.0030 & Reject \\
\hline & LNSCA cannot granger cause LNGDP & 22.20542 & 1 & 0.0000 & Reject \\
\hline & All & 22.24165 & 2 & 0.0000 & Reject \\
\hline \multirow{3}{*}{ LNPT } & LNGDP cannot granger cause LNPT & 5.063531 & 1 & 0.0244 & Reject \\
\hline & LNSCA cannot granger cause LNPT & 4.209052 & 1 & 0.0402 & Reject \\
\hline & All & 6.184553 & 2 & 0.0454 & Reject \\
\hline \multirow{3}{*}{ LNSCA } & LNGDP cannot granger cause LNSCA & 22.69166 & 1 & 0.0000 & Reject \\
\hline & LNPT cannot granger cause LNSCA & 9.758981 & 1 & 0.0018 & Reject \\
\hline & All & 23.44014 & 2 & 0.0000 & Reject \\
\hline
\end{tabular}

subsystems, the pure reference of the coupling cannot reflect the overall efficacy and collaboration level. Therefore, the system coupling coordination degree model $(D)$ is further introduced [34]:

$$
D=\sqrt{C \times T}, \text { where } T=\alpha U_{1}+\beta U_{2}+\chi U_{3} .
$$

In the above formula, $T$ is the comprehensive coordination coefficient of the integrated system, and $\alpha, \beta$, and $\chi$ are the contribution coefficients of the subsystem. In view of the fact that higher education, technological innovation, and the industrial economy are equally important for the development of the social-economic system, the contribution proportions of the three subsystems are assumed to be at the same level $(1: 1: 1)$.

Under the coupling coordination degree model, the coupling coordination degree is divided into four levels [35]: (1) low coordination degree $(0 \leq D<0.4)$, indicating that the coordination of the three subsystems is relatively low; (2) antagonistic running-in $(0.4 \leq D<0.6)$, indicating that the coordination of the three subsystems is not high, and the uncoordinated degree is relatively reduced; (3) moderate coordination $(0.6 \leq D<0.8)$, indicating that the coordination of the three subsystems is relatively good, and specific interaction mechanisms and benign circulation mechanisms have been formed in the subsystems; (4) high coordination $(0.8 \leq D<1)$, indicating that the coordination of the three subsystems is very high, and the interaction mechanisms and benign circulation mechanisms have been formed more deeply and widely in the subsystems.

4.2. Evaluation Index System. In this chapter, there are two main purposes of further exploring the relationship of the above-mentioned three important factors in regional development and evaluating the sustainability of regional development and the quality of economic growth. Therefore, according to the above purposes, the references to the related research of some scholars [36-39], the following of the systemic, scientific, and available principles, and taking into account the indicators' structure of equity, quality, efficiency and benefits, the evaluation index system has been constructed as follows (Table 9). Considering the subsequent standardized method, some negative indicators have been converted into positive indicators according to their economic essence. Therefore, all indicators shown in Table 6 are positive indicators.
4.3. Data Processing. Indicator data from 2010 to 2018 are selected as the samples for this study and come from the corresponding year of the "Guangdong Statistical Yearbook" and "Guangdong Science and Technology Yearbook." Due to the differences in the units, properties, and orders of magnitude of each indicator, it is necessary to standardize the original data in order to eliminate the effects of different dimensions. During the construction of the above index system, a few negative indicators were converted into positive indicators; thus, the following formula is adopted for standardization:

$$
X_{i j}^{*}=\frac{X_{i j}}{\sqrt{\sum_{i=1}^{n} x_{i j}^{2}}},
$$

where $X_{i j}$ is the actual value of the $j$ indicator in the ith system; $i=1,2,3 ; j=1,2,3, \ldots, \mathrm{n}$.

Referring to the ideas of the relevant scholars, the index weight is determined by the entropy method in the objective weighting method [34]. The calculation steps are as follows:

Calculating the proportion of the system corresponding to the standardized indicators, and $m$ represents the number of years:

$$
S_{i j}=\frac{X_{i j}^{\prime}}{\sqrt{\sum_{j=1}^{m} x_{i j}^{\prime}}}
$$

Calculating the entropy of indicator $j$ :

$$
h_{j}=-\frac{1}{\ln m} \sum_{j=1}^{m} s_{i j} \ln s_{i j} \text {. }
$$

Calculating the information utility value of indicator $j$ :

$$
a_{j}=1-h_{j} .
$$

Calculating the entropy weight of indicator $j$ :

$$
w_{j}=\frac{a_{j}}{\sum_{j=1}^{n} a_{j}} .
$$

According to the above calculation steps and the relevant data, the weights of the evaluation index system are calculated (Table 5).

4.4. Results Analysis. According to the above model and calculation steps, the comprehensive development level index and coupling coordination degree of the three 
Response to Cholesky One S.D. (d.f. adjusted) Innovations ?2 S.E. Response of LNGDP to LNSCA

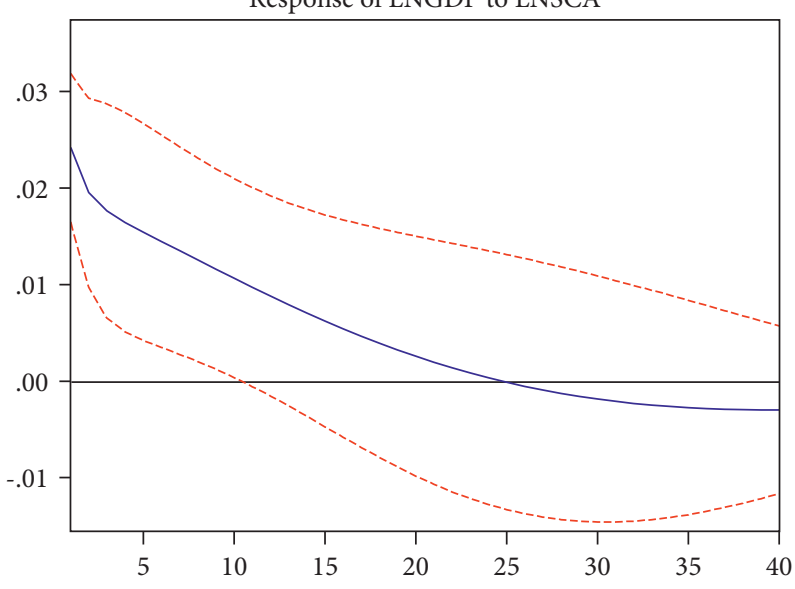

(a)

Response to Cholesky One S.D. (d.f. adjusted) Innovations ?2 S.E. Response of LNPT to LNSCA

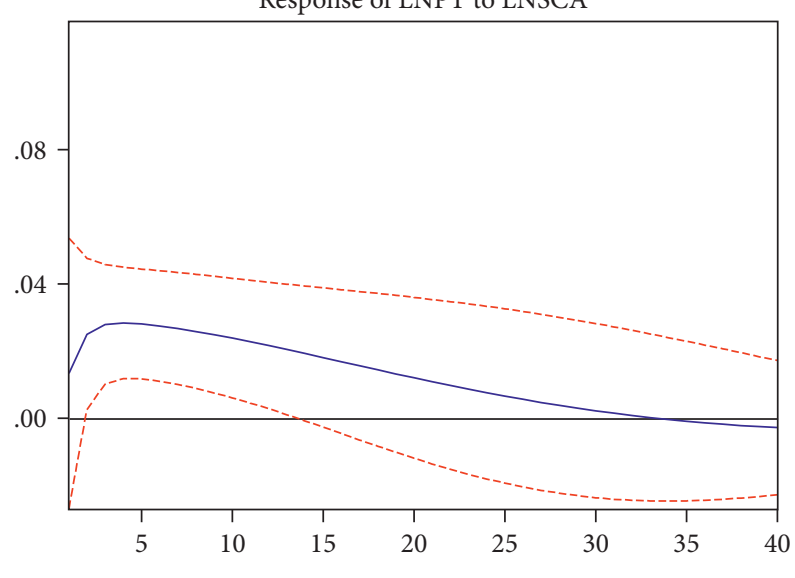

(c)
Response to Cholesky One S.D. (d.f. adjusted) Innovations ?2 S.E. Response of LNGDP to LNPT

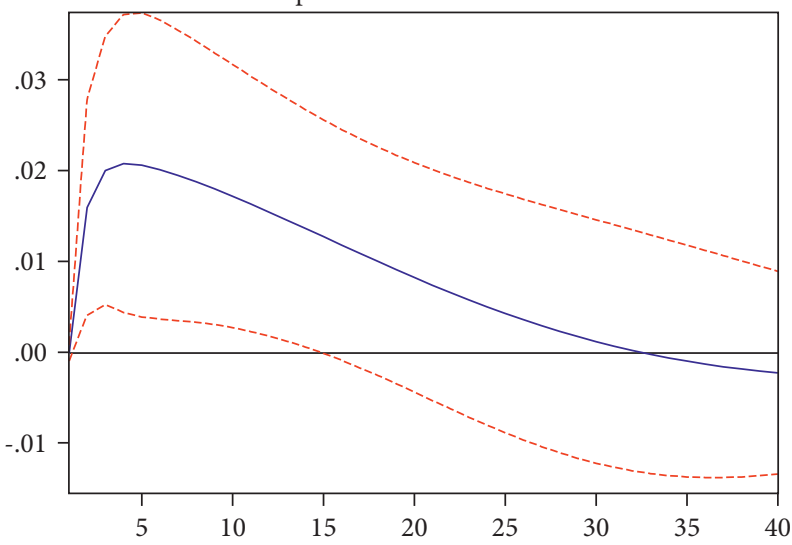

(b)

Response to Cholesky One S.D. (d.f. adjusted) Innovations ?2 S.E. Response of LNPT to LNGDP

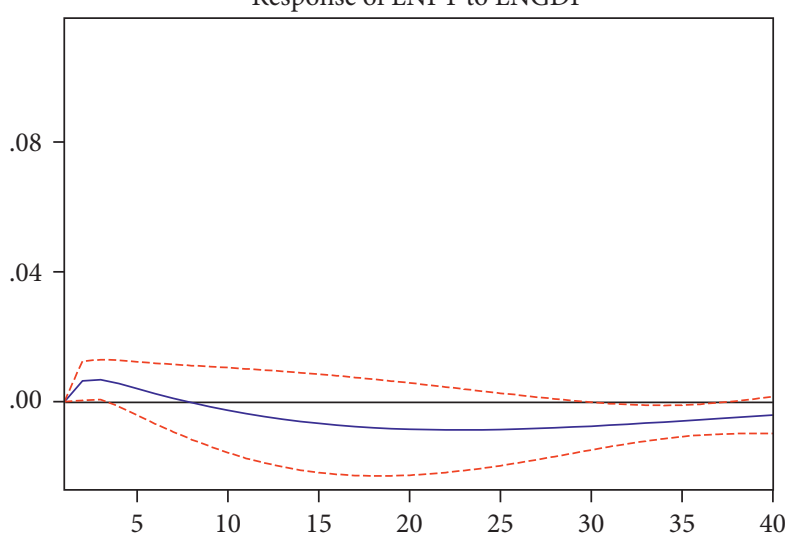

(d)

Figure 2: Impulse response of the VAR model.

subsystems in Guangdong Province from 2010 to 2018 were obtained (Table 10 and Figure 3). In general, the coupling degree of the three subsystems is very high, with a nine-year average of 0.9912 , which further validates the relationships between higher education, technological innovation, and economic growth, as mentioned in the literature review and the previous chapter. The coupling coordination degree of the three subsystems is not very good, with a nine-year average of 0.5636 , which partly validates the uncoordinated development among higher education, technological innovation, and the regional economy. Furthermore, the results also indirectly imply the potential problems of the regional sustainable development and the economic growth quality.

According to Table 7 and Figure 3, the specific analyses are as follows:

(i) There is a close interaction between the higher education subsystem and industrial economic subsystem, and their comprehensive development index horizontal trend lines are highly consistent.
Only in recent years has the comprehensive development level of the higher education subsystem exceeded the industrial economy subsystem. This was due to the local government increasing input into higher education, with an average annual growth rate of $12.55 \%$ from 2015 to 2018 .

(ii) The comprehensive development level of the technological innovation subsystem has increased rapidly, as compared to the other two subsystems. Additionally, it has surpassed the other two subsystems in recent years. These results indicate that the transformation trend from factor-driven and investment-driven to innovation-driven development models has become obvious. At the same time, the comprehensive development level gap between the technological innovation subsystem and industrial economy subsystem has increased, which indirectly indicates that the transformation efficiency and industrialization degree of technological innovation achievements need to be further 
TABLE 8: Variance decomposition of LNGDP.

\begin{tabular}{|c|c|c|c|c|c|}
\hline Variable & Period & S.E. & LNGDP & LNPT & LNSCA \\
\hline \multirow{12}{*}{ LNGDP } & 1 & 0.024259 & 100.0000 & 0.000000 & 0.000000 \\
\hline & 2 & 0.035007 & 78.25687 & 21.01142 & 0.731712 \\
\hline & 3 & 0.044097 & 64.55741 & 34.04610 & 1.396484 \\
\hline & 4 & 0.051582 & 56.75761 & 41.27758 & 1.964804 \\
\hline & 19 & 0.091443 & 33.35727 & 57.76407 & 8.878655 \\
\hline & 20 & 0.092054 & 32.96385 & 57.81200 & 9.224146 \\
\hline & 21 & 0.092562 & 32.62687 & 57.82664 & 9.546490 \\
\hline & 22 & 0.092982 & 32.34198 & 57.81318 & 9.844840 \\
\hline & 37 & 0.095039 & 31.70763 & 56.62420 & 11.66817 \\
\hline & 38 & 0.095115 & 31.76025 & 56.57171 & 11.66804 \\
\hline & 39 & 0.095193 & 31.81163 & 56.52674 & 11.66163 \\
\hline & 40 & 0.095272 & 31.86064 & 56.48903 & 11.65032 \\
\hline
\end{tabular}

TABLE 9: Evaluation indicators index system and weight.

\begin{tabular}{|c|c|c|}
\hline Subsystem & Indicators & Weight \\
\hline \multirow{6}{*}{$\mathrm{U}_{1}$} & Student scale learning in school & 0.0599 \\
\hline & Number of graduate students & 0.1081 \\
\hline & Number of full-time teachers at professorial level & 0.1493 \\
\hline & Local higher education outlay & 0.5431 \\
\hline & Teacher-student ratio & 0.0574 \\
\hline & Gross enrolment ratio in higher education & 0.0822 \\
\hline \multirow{6}{*}{$\mathrm{U}_{2}$} & R\&D fund & 0.1322 \\
\hline & Internal expenditure of $\mathrm{R} \& \mathrm{D}$ fund & 0.1316 \\
\hline & Sales revenue of new products & 0.1650 \\
\hline & Number of patents authorized & 0.1950 \\
\hline & Output value of high and new technology industry & 0.0859 \\
\hline & Technical contract turnover & 0.2904 \\
\hline \multirow{8}{*}{$\mathrm{U}_{3}$} & GDP per capita & 0.1426 \\
\hline & Resident per disposable income & 0.1647 \\
\hline & Comparison of consumption level of urban and rural residents (urban $=1$ ) & 0.1099 \\
\hline & Per capita output in secondary sector of the economy & 0.1024 \\
\hline & Per capita output in tertiary sector of the economy & 0.1415 \\
\hline & Total imports and exports & 0.1432 \\
\hline & Total imports and exports/GDP & 0.1178 \\
\hline & Industrial value added above scale/total energy consumption & 0.0779 \\
\hline
\end{tabular}

$U_{1}$ represents the higher education system; $U_{2}$ represents the technological innovation system; $U_{3}$ represents the industrial economic system.

improved in order to meet the requirements of the high-quality development stage in the future.

(iii) Compared to the other two subsystems, the comprehensive development level of the industrial economic subsystem has been kept in a more moderate growth trend, suggesting that economic growth is affected not only by higher education and technological innovation but also by other factors (this is of course also the reason that the indicators used in this study mostly reflect the quality and sustainability of economic development). In addition, this trend indicates that there are still some issues that need to have more attention paid to them and urgently need to be solved in the high-quality economic development stage, such as unbalanced and uncoordinated regional development.

In general, from 2010 to 2018, the coupling coordination degree of the three subsystems maintained a stable growth trend, indicating that, since the 12th five-year plan period, the three subsystems have significantly interacted and promoted each other. From the perspective of the specific value, the overall coordination level is not high enough despite the steady improvement, with a mean value of 0.5636 in nine years and the moderate coordination state achieved only in the last three years. The results show that the synergistic effect of mutual promotion and coordinated development among the three subsystems has not been afforded full attention, and this is incompatible with the requirements of high-quality economic development.

4.5. Reflection. As shown in the empirical results, the lessquality coupling coordination degree of the three subsystems reflects the less-quality economic growth and potential issues that hinder regional sustainable development of Guangdong Province compared with its economic aggregate 
TABLE 10: Subsystem development index and coupling coordination degree (2010-2018).

\begin{tabular}{lccccccc}
\hline Year & $\mathrm{U} 1$ & $\mathrm{U} 2$ & $\mathrm{U} 3$ & $\mathrm{~T}$ & $\mathrm{C}$ & $\mathrm{D}$ & Coordination degree \\
\hline 2010 & 0.2421 & 0.1472 & 0.2474 & 0.2123 & 0.9734 & 0.4545 & Low coordination \\
2011 & 0.2677 & 0.1762 & 0.2732 & 0.2390 & 0.9808 & 0.4842 & Low coordination \\
2012 & 0.2904 & 0.2074 & 0.2891 & 0.2623 & 0.9882 & 0.5091 & Antagonistic running-in \\
2013 & 0.3024 & 0.2532 & 0.3118 & 0.2891 & 0.9959 & 0.5366 & Antagonistic running-in \\
2014 & 0.3205 & 0.2718 & 0.3339 & 0.3088 & 0.9961 & 0.5546 & Antagonistic running-in \\
2015 & 0.3512 & 0.3209 & 0.3456 & 0.3392 & 0.9992 & 0.5822 & Antagonistic running-in \\
2016 & 0.3902 & 0.3705 & 0.3566 & 0.3724 & 0.9993 & 0.6101 & Moderate coordination \\
2017 & 0.4377 & 0.4424 & 0.3848 & 0.4216 & 0.9980 & 0.6487 & Moderate coordination \\
2018 & 0.4812 & 0.5680 & 0.4026 & 0.4839 & 0.9902 & 0.6922 & Moderate coordination \\
Average & 0.3426 & 0.3064 & 0.3272 & 0.3254 & 0.9912 & 0.5636 & Antagonistic running-in \\
\hline
\end{tabular}

and regional innovation ability. This may be the result of the long-term unbalanced regional development model adopted by the local government, and the uncoordinated development between and within higher education and regional economy, as well as other underlying impacts. In view of the complexity of these reasons, we will take further analysis and demonstration in the next chapter combined with detailed local socioeconomic data and performance.

\section{Further Discussion and Implications}

5.1. Theoretical Mechanisms and Paths on the Quantity and Quality of Economic Growth. In order to better understand the underlying causes behind the above conflict between the quantity and quality of economic growth, this paper takes higher education as an example and summarizes the mechanisms and corresponding paths of higher education on the quantity and quality of economic growth, according to the related researches mentioned above in literature review and the empirical results in the third and fourth parts of this paper (Figure 4).

First of all, from the perspective of human capital theory, higher education directly improves total factor productivity (TFP) to promote economic growth by enhancing the quality of human capital, and indirectly promote regional economic development through advancing human capital structure to optimize and upgrade the industrial structure. In the other hand, from the perspectives of innovation theory, higher education promotes economic growth by knowledge creation and $\mathrm{R} \& \mathrm{D}$ cooperation with industrial organizations and research institutions in the regional innovation ecosystem.

In the above two main paths, there are three main differentiation mechanisms that affect the quality and quantity of economic growth in the regional development: (1) The scale of human capital influences the quantity of economic growth, while the quality and structure of human capital influences the quality of economic growth; (2) similar to the effect of human capital, the scale of higher education affects the quantity of economic growth, while the quality and structure of higher education affects the quality of economic growth; (3) the degree of regional development differences affects the circular cumulative effect within and between higher education subsystem, innovation subsystem, and industrial economy subsystem (the circular cumulative effect is strong in developed areas while not obvious or even not in undeveloped areas, and this differential impact eventually led to the "Matthew effect" presented as "the strong get stronger and the weak get weaker") [38-40].

Note: The blue dotted line with arrowheads indicates the path of circular cumulative effect.

\subsection{Actual Date and Performance inside and outside the Local Region}

5.2.1. Unbalanced Development in a Regional Social Economy. The socioeconomic development in this region is unbalanced and inadequate from the perspective of regional development. Guangdong Province can be divided into four regions according to geographical location: the Pearl River Delta area, the Eastern area, the Western area, and the Northern area. As shown in Table 11, the Pearl River Delta area has been the most developed within the province and reached a middle-to-upper level that is close to the level of high-income countries and regions according to the national and regional income standards established by the World Bank. Compared to the Pearl River Delta, the other three areas have been significantly underdeveloped within the province.

The above data and phenomena illustrate the typical polarized and unbalanced development model. Under this model, income differences and inequality caused by regional economic difference promotes economic growth in developed regions, but it also hinders economic growth in poor regions, and finally led to the formation of the "Matthew effect" [39]. In addition, in the process of unbalanced development, technology transfer often occurs between strong regions and presents the "Matthew effect" [41, 42]. Therefore, these Matthew effects hinder the role of higher education in the economic development of less-developed areas in Guangdong Province.

5.3. Uncoordinated Scale, Quality, and Structure in Regional Higher Education. First of all, the higher education scale does not match the strong economic status from the perspective of the province and will be the underlying impact for the high-quality development. From 2016 to 2018, the gross enrolment rate of higher education in Guangdong 


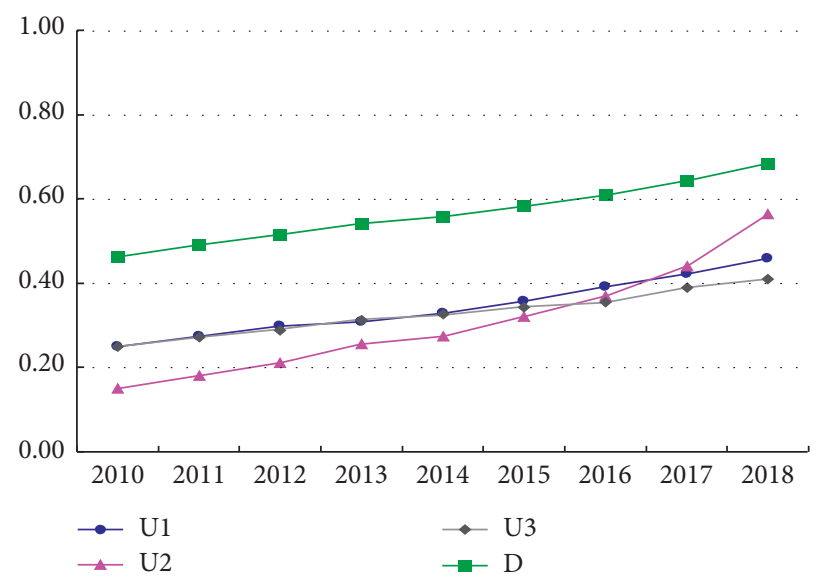

FIGURE 3: Subsystem development index and coupling coordination degree trend (2010-2018).

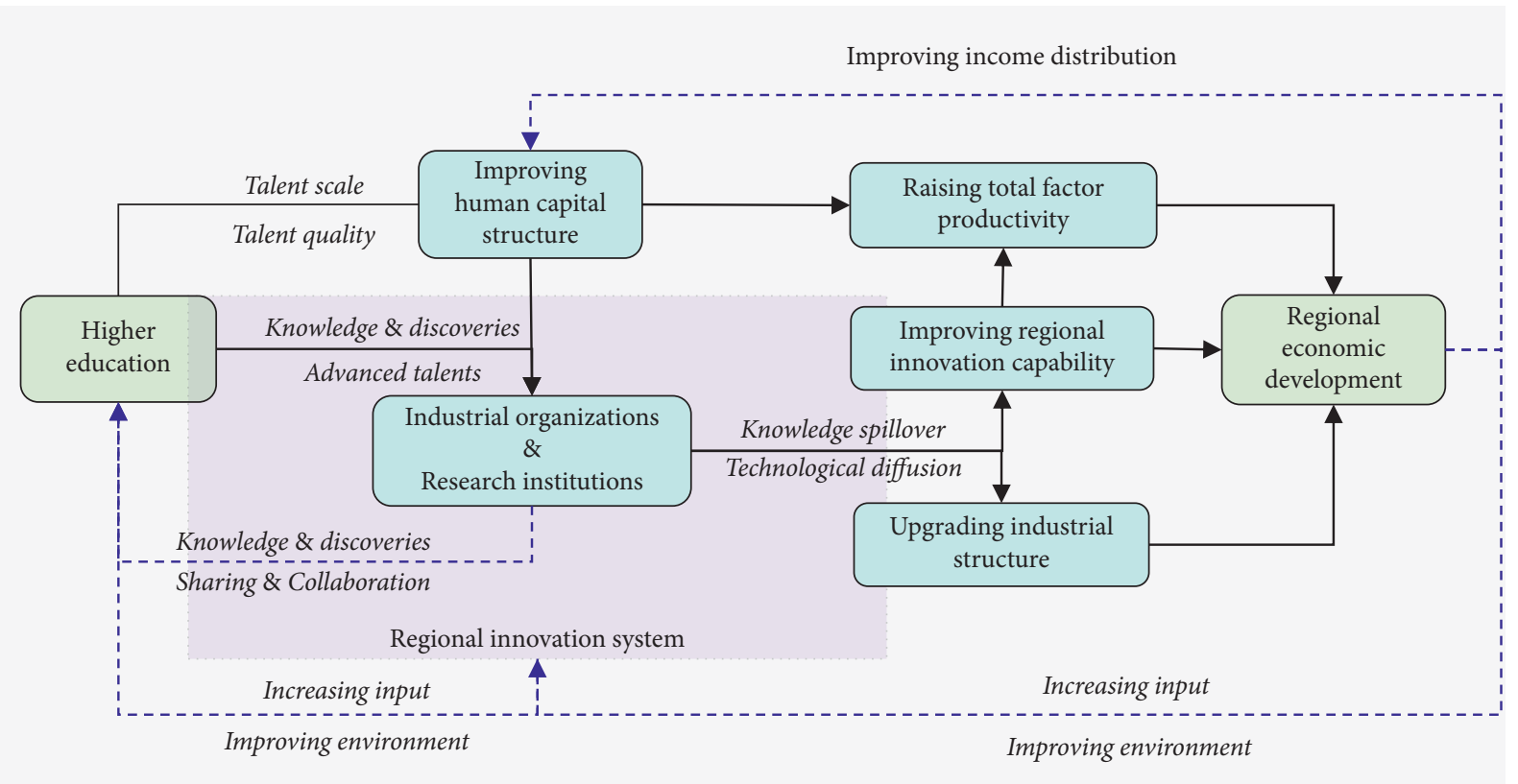

Figure 4: Paths and mechanisms of higher education on regional economic development.

Province was $35.1 \%, 38.7 \%$, and $42.4 \%$, while in China as a whole, it was $42.7 \%, 45.7 \%$, and $48.1 \%$.

On the other hand, the regional distribution structure of HEIs is unreasonable. The HEIs of a high quality are concentrated in the Pearl River Delta area, especially Guangzhou and Shenzhen, and these two cities together have $90 \%$ of the province's master degree education institutions. Higher education different resource allocation and development quality have led to the "Matthew effect" both in higher education itself and income distribution between the Pearl River Delta area and other three areas $[42,43]$. Meanwhile, higher education in developed regions helps to reduce the income gap while the opposite is true in undeveloped regions, and the "Matthew effect" in income distribution caused by the fairness of higher education is more pronounced in economic crises and poor economic environments [25].
In addition, in undeveloped areas, the local government's willingness and ability to increase higher education input is lower than for basic education and secondary education due to the weak financial strength and higher education externality. These phenomena, in turn, have weakened the endogenous driving force and led to slow development in these areas. Therefore, the equity and quality of higher education in the other three areas cannot be effectively improved, which has affected its role in technological innovation and economic growth.

\subsection{Unreasonable Structure and Flow in Regional Human} Capital. From the perspective of the human resource structure, Guangdong Province's economic development depends on demographic bonuses more than talent bonuses. As one of China's developed provinces, Guangdong 
TABle 11: Comparison of some social-economic indicators in different areas in 2018.

\begin{tabular}{lcccc}
\hline Areas & GDP growth rate (\%) & GDP per capita (US \$) & R\&D input intensity (\%) & Population urbanization rate (\%) \\
\hline Pearl river delta & 6.9 & 19372 & 3.19 & 85.91 \\
Eastern guangdong & 6.3 & 5705 & 0.82 & 52.70 \\
Western guangdong & 5.4 & 6875 & 0.38 & 52.70 \\
Northern guangdong & 4.1 & 5190 & 0.61 & 49.73 \\
Guangdong province & 6.8 & 12858 & 2.78 & 70.70 \\
China & 6.6 & 9613 & 2.19 & 59.58 \\
\hline
\end{tabular}

Source: Guangdong Statistical Yearbook 2019 and China Statistical Yearbook 2019.

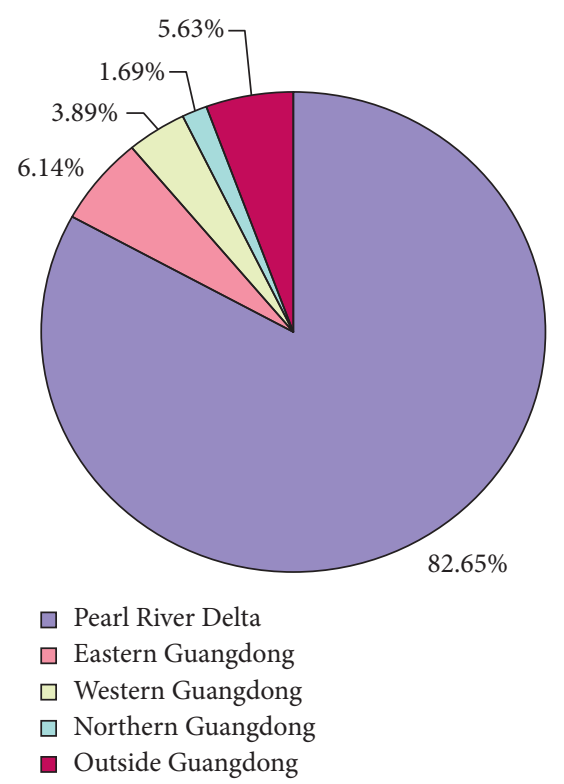

FIGURE 5: Regional structure of HEI employment in Guangdong Province in 2018 (source: 2018 annual report on the employment quality of university graduates in Guangdong Province).

Province has obvious advantages in terms of the labor force and talent gathering. However, the proportion of the employed population with higher education of Guangdong Province was $0.27 \%$ lower than the national average, $3.53 \%$ and $1.82 \%$ lower than those of Jiangsu Province and Zhejiang Province according to "China's 2015 national sample survey of $1 \%$ for the population"(taken by the National Bureau of Statistics of the People's Republic). Therefore, the quality of the human capital structure mentioned above affects the coordination between higher education and regional economic development at the provincial level [44].

Additionally, the interaction path between local HEIs and local social development has not been effectively established in areas outside the Pearl River Delta. As can be seen from Figure 5, in 2018, there were 473,000 graduates employed from HEIs in Guangdong Province (graduates studying further and employed abroad were outside of the statistical range); among them, $82.65 \%$ chose the Pearl River Delta area, only $11.72 \%$ chose the three other areas of Guangdong Province, and $5.63 \%$ chose other provinces in China. Therefore, the talents siphon effect in the Pearl River Delta area contrasts sharply with the talent drains in the other three areas. The above phenomena restrain the effect of higher education on economic growth and also inhibit the supporting role played by higher education in the regional innovation ecosystem.

\section{Conclusions}

In conclusion, taking a developed region in a developing country as an example, this study discusses the relationship between higher education, technological innovation, and economic growth, the coordinated development of the subsystems where the above three elements are located, as well as the sustainability of regional development and quality of economic growth. Furthermore, it summarizes the mechanisms and corresponding paths of higher education on the quantity and quality of economic growth and illustrates the interactive relationships, the dynamic mechanisms, and the influencing factors with the detailed date and practical performance [45].

Higher education and technological innovation are crucial to the innovation ecosystem and economic growth, and they play significant roles in the formation of endogenous driving forces in regional development. However, the roles have been confined due to the unbalanced development model, with polarization and the "Matthew effect." In the early 1990s, in order to achieve a rational allocation of 
limited resources to maximize economic returns, Guangdong Province established a gradient development strategy and an unbalanced development model with an efficiency priority to provide more generous resources to the Pearl River Delta area. Under the above strategy and model, the Pearl River Delta area succeeded in leapfrogging development and has been becoming one of the most innovative regions in the world. In sharp contrast to this, the three other areas outside the Pearl River Delta have been underdeveloped. This polarization phenomenon suggests that the siphon effect of the Pearl River Delta has been continuously strengthened, while the spillover effect has not been fully released, and also reflects the potential issues regarding the sustainability of regional development and the quality of regional economic growth. Additionally, talent, technology, and capital will be further concentrated in the Pearl River Delta area with the implementation of the outlined development plan for the "Guangdong-Hong Kong-Macao Greater Bay Area." Thus, this highlights the challenges that areas outside the Pearl River Delta are facing, which have become bottlenecks of regional sustainable development and the high-quality economic development in Guangdong Province.

Strengthening more coordinated development is now urgently required in the regional sustainable development context and high-quality development stage. Firstly, higher education should be more enhanced in the regional development framework and outline, be more targeted at the interaction and synergy between the higher education subsystem, innovation subsystem, and industrial economy subsystem, and be given more consideration of equity, quality, and sustainability. Secondly, an open innovation ecosystem should be constructed with regional and organizational boundaries that are broken down to promote the cooperation that emerges in different ways and embeds in different subsystems. In particular, the cooperation between developed and underdeveloped regions should be further strengthened in order to accelerate knowledge spillover and technology diffusion. Thirdly, the deadlock of the "Matthew effect" should be gradually alleviated or broken down by the circular cumulative effect formed on the path of high-quality development. The negative effects of the "Matthew effect" and the lack of cumulative circular effects in undeveloped areas have become the major obstacles on the path to the high-quality development of the whole province. Thus, the input mechanism of the provincial-municipal coconstruction model in higher education and the cross-regional and cross-organizational cooperation mechanism in the construction of the regional innovation system needs to be further improved by both the provincial and municipal governments. Fourth, the governments of underdeveloped areas should establish a conjugate driving mechanism for higher education input and talent gathering input. This is an effective countermeasure to deal with the siphon effect of the Pearl River Delta and local brain drain. They should pay more attention to the structure and combination policies that can attract and retain talents, and input more to create better employment for the environment, business, innovation, and living.

\section{Data Availability}

Indicator data from 1998 to 2018 were selected as the sample for this study, which were taken from the corresponding year of the "China Statistical Yearbook" and "Guangdong Statistical Yearbook."

\section{Ethical Approval}

All the study procedures were approved by the Ethics Committee of the Zhaoqing University.

\section{Consent}

Informed consent of participation was implied through survey completion.

\section{Conflicts of Interest}

The authors declare that the research was conducted in the absence of any commercial or financial relationships that could be construed as a potential conflict of interest.

\section{Authors' Contributions}

HJL and SL conceived and designed the study. HJL and SL collected and analyzed the data. SL interpreted the data and drafted the manuscript. HJL reviewed and edited the manuscript.

\section{Acknowledgments}

This research was funded by the 2017 Guangdong Province Colleges and Universities Featured Innovation Project (No. 2017WTSCX118), 2018 Guangdong Province Higher Education Teaching Reform Project (No. 2018613), National Education Science 13th Five-Year Plan Project (No. EIA200409), and 2017 Central government supports special fund projects for the Development Of Local Colleges and Universities (No. Z20170043).

\section{References}

[1] T. W. Schultz, "Investment in human capital," The American Economic Review, vol. 51, no. 1, pp. 1-17, 1961.

[2] G. S. Becker, "Investment in human capital: A theoretical analysis," Journal of Political Economy, vol. 70, no. 5, pp. 9-49, 1962.

[3] R. E. Lucas, "On the mechanics of economic development," Journal of Monetary Economics, vol. 22, no. 1, pp. 3-42, 1988.

[4] P. Cooke, "Regional innovation systems: competitive regulation in the new europe," Geoforum, vol. 23, no. 3, pp. 365-382, 1992.

[5] B. A. Lundvall, National Systems of Innovation, Printer Publisher, London, UK, 1992.

[6] R. R. Nelson, National System of Innovation: A Comparative Study, Oxford University Press, New York, NY, USA, 1993.

[7] R. Mekvabidze, "From business modeling to business management: an exploratory study of the optimal decision making on the modern university level," Journal of Logistics, Informatics and Service Science, vol. 7, no. 1, pp. 67-86, 2020. 
[8] R. M. Solow, "A contribution to the theory of economic growth," Quarterly Journal of Economics, vol. 70, no. 2, pp. 65-94, 1956.

[9] P. M. Romer, "Increasing returns and long-run growth," Journal of Political Economy, vol. 94, no. 5, pp. 1002-1037, 1986.

[10] P. M. Romer, "Endogenous technological change," Journal of Political Economy, vol. 98, no. 5, pp. 71-102, 1990.

[11] H. Etzkowitz and L. Leydesdorff, "The Triple helix--university-industry-government relations," A Laboratory for Knowledge Based Economic Development, vol. 14, no. 1, pp. 14-19, 1995.

[12] H. Etzkowitz and M. Klofsten, "The innovating region: toward a theory of knowledge-based regional development," $R$ \& $D$ Management, vol. 35, no. 3, pp. 243-255, 2005.

[13] D. F. Shaffer, "Higher education systems are assuming a larger role in the economic development efforts of their states," Economics, Management, and Financial Markets, vol. 10, no. 1, 2015.

[14] L. Alo and R. Kärt, "How higher education institutions contribute to the growth in regions of europe," Studies in Higher Education, vol. 42, no. 1, pp. 65-78, 2017.

[15] Y. Cai, "From an analytical framework for understanding the innovation process in higher education to an emerging research field of innovations in higher education," The Review of Higher Education, vol. 40, no. 4, pp. 585-616, 2017.

[16] Y. M. Jin, "Developing joint R\&D institutes between Chinese universities and international enterprises in China's innovation system: a case at tsinghua university," Sustainability, vol. 11, no. 24, p. 7133, 2019.

[17] K. Richa, "Co-creation for social innovation in the ecosystem context: the role of higher educational institutions," Sustainability, vol. 12, no. 1, Article ID 3072020, 2018.

[18] G. Zhou and S. Luo, "Higher education input, technological innovation, and economic growth in China," Sustainability, vol. 10, no. 8, p. 278, 2018.

[19] B. Oancea, R. Pospisil, and M. Dragoescu, "Higher education and economic growth: a comparison between the Czech republic and Romania," Prague Economic Papers, vol. 3, p. 23, 2017.

[20] J. Heckman and R. Hai, "Inequality in human capital and endogenous credit constraints," Review of Economic Dynamics, vol. 25, no. 1, pp. 4-36, 2017.

[21] R. Vernon, "The preparation of this article was financed in part by a grant from the Ford Foundation to the Harvard Business School to support a study of the implications of United States foreign direct investment. This paper is a byproduct of the hypothesis-building stage of the study," International Economic Policies and their Theoretical Foundations, vol. 18, pp. 415-435, 1992.

[22] X. Li, "State power, symbolic capital, and the hierarchy and homogeneity of higher education in China: in the example of three key universities policies after the founding of new China," Peking University Education Review, vol. 16, no. 2, pp. 134-150, 2018.

[23] K. M. Robert, "The Matthew effect in science-the Re-ward and communication systems of science are considered," Science, vol. 159 , pp. 56-63, 1968.

[24] L. Xin, "Interpreting the Matthew effect in the development of higher education-the analysis over internal cause of unbalanced development in present China's higher education," Education Science, vol. 29, no. 1, pp. 28-31, 2013.

[25] N. Yang and K. Wang, "Statistical analysis of Matthew effect between higher education inequality and income inequality - an empirical study of the case in U.S." Fudan Education Forum, vol. 9, no. 1, pp. 61-66, 2011.

[26] A. Ciccone and E. Papaioannou, "Human capital, the structure of production, and growth," The Review of Economics and Statistics, vol. 91, no. 1, pp. 66-82, 2009.

[27] C. R. Vaz and P. M. Selig, "Maturity assessment model of intellectual capital for manufacturing organization," IEEE Latin America Transactions, vol. 14, no. 1, pp. 206-219, 2016.

[28] X. Xue and L. Li, "An analysis of international empirical research on the relationship between higher education and economic growth," Renmin University of China Education Journal, vol. 1, pp. 76-87, 2018.

[29] C. A. Sims, "Macroeconomics and reality," Econometrica, vol. 48 , no. 1 , pp. $1-48,1980$.

[30] G. Zhao and S. Luo, "Higher education input, technological innovation, and economic growth in China," Sustainability, vol. 10, no. 8, p. 2615, 2018.

[31] H. Sun and H. Wei, "Empirical research on the relationship between the layer structures of higher education and regional economic development," Journal of Industrial Technological Economics, vol. 34, no. 10, pp. 69-76, 2015.

[32] C. Xu, "An empirical study on the relationship among higher education, human capital and regional economic growth based on Guangdong," Research in Higher Education of Engineering, vol. 2, pp. 90-96, 2013.

[33] Z. Zeng, "The analysis of coordination and sustainable development," Systems Engineering theory \& Practice, vol. 3, pp. 18-21, 20101.

[34] Y. Liu, R. Li, and X. Song, "Analysis of coupling degrees of urbanization and ecological environment in chian," Journal of Natural Resources, vol. 20, no. 1, pp. 105-112, 2005.

[35] L. Jiang, L. Bai, and Y. Wu, "Coupling and coordinating degrees of provincial economy, resources and environment in China," Journal of Natural Resources, vol. 32, pp. 788-799, 2017.

[36] X. Xie, "Study on the coupling coordination degree of technological progress and economic growth quality-an example of beijing-tianjin-hebei region," Journal of Industrial Technological Economics, vol. 39, no. 2, pp. 134-140, 2020.

[37] M. Song and M. Li, "The coupling degree and its determinants of higher education, Scientific and technological innovation and economic development in China," Modern Education Management, vol. 3, pp. 19-25, 2019.

[38] R. Zhao and X. Han, "On coordinated development of higher education, innovation ability and economic growth-A case study of henan province," Heilongjiang Researches on Higher Education, vol. 37, no. 2, pp. 23-29, 2019.

[39] R. J. Barro, "Inequality and growth in a panel of countries," Journal of Economic Growth, vol. 5, no. 1, pp. 5-32, 2000.

[40] S. A. Hu and L. Jin, "Appropriate"Policy Grades"is key alterative of regional harmonization development-in view of causal circulation mechanism of new economic geography," Academic Monthly, vol. 42, no. 1, pp. 73-79, 2010.

[41] L. Yang and X. Liu, "Is there "Matthew Effect" in regional technology Transfer? The driving orientation of inter-regional technology transfer," Studies in Science of Science, vol. 32, no. 12, pp. 1820-1827, 2014.

[42] J. He and M. Chen, "Exploratory analysis on Matthew effect in Guangdong regional innovation development," Science and Technology Management Research, vol. 39, no. 17, pp. 7-11, 2019.

[43] K. Sylwester, "Enrolment in higher education and changes in income inequality," Bulletin of Economic Research, vol. 55, no. 3, pp. 249-262, 2003. 
[44] S. Orazi, L. B. Martinez, and H. Vigier, "A regional kohonen map of financial inclusion and related macroeconomic variables," Economic Computation \& Economic Cybernetics Studies \& Research, vol. 54, no. 3, pp. 179-195, 2018.

[45] R. Islam, "Designing sustainable parameters for facilities management to improve operational efficiency," Journal of System and Management Sciences, vol. 9, no. 2, pp. 1-22, 2019. 